\title{
Mother and Home Visitor Emotional Well-Being and Alignment on Goals for Home Visiting as Factors for Program Engagement
}

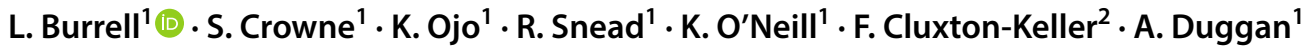

Published online: 31 May 2018

(C) The Author(s) 2018, Corrected publication August/2018

\begin{abstract}
Objectives Family engagement in home visiting (HV), as indicated by length of enrollment, is a major challenge as most families do not stay enrolled for the intended duration prescribed by HV models. This study examined maternal and visitor emotional well-being as factors for maternal satisfaction with the program in addressing reasons for enrolling in HV and program engagement and the role of their working alliance with the visitor as a mediator of this. Methods Longitudinal data were collected from 148 mothers and 54 visitors in $21 \mathrm{HV}$ programs. Mothers completed surveys shortly after enrolling and 6 months later to assess attributes of the working alliance with their visitor. Visitors completed a survey to assess work-related well-being. HV program data were used to measure engagement. Results Mothers enrolled for multiple, diverse reasons, most often to promote child development and parenting (96\%). Mothers' satisfaction with program efforts to address reasons for enrollment was highest for parenting (79\%) and lowest for jobs and education (30\%). Results of the mediational path model indicated that ratings of the visitor on goal alignment were positively associated with engagement. Maternal emotional availability and visitor work-related emotional exhaustion were negatively associated with engagement. Exploratory analyses suggested that ratings of the visitor on goal alignment were a stronger predictor of engagement for mothers with low emotional availability compared to other mothers. Conclusions for Practice Visitor alignment with mothers on goals and responsiveness to reasons for enrolling appear to be effective in promoting engagement. Individualizing services to reflect maternal goals and emotional capacity may be important strategies to address engagement challenges.
\end{abstract}

Keywords Home visiting $\cdot$ Maternal satisfaction $\cdot$ Engagement $\cdot$ Emotional well-being

\section{Significance}

Family engagement continues to be an important issue facing home visiting field; studies find that most families do not receive the intended amount of services. Previous studies have documented attributes of visitors and families that are associated with HV engagement. This study extends previous investigations into attributes of mothers and visitors associated with HV engagement by considering mothers' reasons for enrolling and their visitors' alignment with and attention to these reasons.

\section{Burrell}

lburrell@jhu.edu

1 Department of Population, Family and Reproductive Health, Johns Hopkins Bloomberg School of Public Health, 615 N. Wolfe Street, Baltimore, MD 21205, USA

2 Dartmouth Geisel School of Medicine, 1 Rope Ferry Road, Hanover, NH 03755-1404, USA

\section{Introduction}

Family engagement, most commonly defined as the length of enrollment or the frequency of home visits, has been a major challenge for home visiting (MIECHV TACC, 2015). Most evidence-based home visiting models intend to serve families for 2-3 years with intensive visit schedules and research suggests that engagement rates fall well below expectations. In fact, typically $40-50 \%$ of families leave within 1 year (Boller et al. 2014; Duggan et al. 2007). Because engagement remains a challenge, research to promote it is a national priority (Duggan et al. 2013).

Studies have documented attributes of visitors and families that are associated with engagement (Cho et al. 2017; Latimore et al. 2017; O'Brien et al. 2012). For example, Latimore et al. (2017) found that visitor morale was associated with receiving a high dose of services. Maternal age, race, and pregnancy status are commonly associated with engagement (Daro et al. 2003; McGuigan et al. 2003; 
O'Brien et al. 2012). Other maternal characteristics, including depression and relationship security, may influence engagement (Girvin et al. 2007; Sharp et al. 2003). Relationship security is the extent to which an adult provides and receives support in relationships, including one formed between a mother and visitor. McFarlane et al. (2010) found that mothers with anxious relationship styles were more likely to receive a high dose of service, suggesting that they may be particularly open to developing a close relationship with the visitor. Mikulincer and Nachshon (1991) found associations between relationship avoidance and a lack of self-disclosure, which may make it harder for a visitor to identify the mother's needs.

Home visiting values a strong alliance between visitors and mothers to help mothers reach their goals. Mothers choose to enroll for many reasons, such as wanting information about job training, child development, and tangible assistance (Stevens et al. 2005; Tandon et al. 2008). Visitors respond to these reasons in varied ways. For instance, Tandon et al. (2008) found that visitors were most likely to meet the needs that were more proximal to program goals such as parenting information.

The nature of the mother's working alliance with the visitor is predictive of family engagement. Studies have shown that mothers with better relationships with their visitors were more likely to have higher levels of program involvement and complete the program (Girvin et al. 2007; Korfmacher et al. 2007). Evidence suggests that this working alliance may be impacted by characteristics of the mother and the visitor. For example, mothers with both severe depression and discomfort with trusting others had lower ratings of trust in their visitor (Cluxton-Keller et al. 2014).

The Maternal, Infant, and Early Childhood Home Visiting (MIECHV) Program was established in 2010 to expand evidence-based home visiting and to carry out research to study its implementation and effectiveness. ${ }^{1}$ The current study aims to: (a) describe mothers' reasons for enrolling, (b) examine the associations of maternal and visitor characteristics with mothers' ratings of their working alliance with their visitors, (c) examine the association of attributes of the working alliance with program engagement, and (d) explore the role of the working alliance as a mediator of associations of maternal and visitor characteristics with program engagement.

\section{Methods}

\section{Setting and Participants}

With State and Federal MIECHV funding, the New Jersey Departments of Health and Children and Families are collaborating to build the state's home visiting program (NJ$\mathrm{HV}$ ). The evaluation of NJ-HV incorporates mixed methods to inform strategies to improve engagement and outcomes by strengthening the implementation system. This paper uses data from a longitudinal study of a purposive sample of mothers newly enrolling in home visiting. The research was conducted in accord with prevailing ethical principles and approved by the Johns Hopkins School of Medicine and state Institutional Review Boards. Study participants provided written informed consent and were remunerated for data collection.

In 2012, NJ-HV funded 33 home visiting program sites statewide. Each site used one of three evidence-based models: Healthy Families America (HFA), Nurse-Family Partnership (NFP), and Parents as Teachers (PAT). Sites were eligible for this study if they had operated for at least 2 years ${ }^{2}$ and had at least three visitors who had completed a web-based survey. Visitors were eligible if they had completed core training and were able to visit families independently. In total, 95 visitors in 21 program sites were eligible for this study (27 visitors across 13 HFA sites, 27 visitors across 7 NFP sites, 3 visitors from 1 PAT site).

A maximum of three mothers per eligible visitor were recruited between June 2012 and March 2013. Researchers trained visitors to identify eligible mothers and introduce the study within the first three visits. A mother was eligible for the study if she: (a) was pregnant or had an infant less than 3 months old; (b) received services in English or Spanish; and (c) was assigned to a visitor who had not recruited three families.

During recruitment, 730 mothers enrolled in services. Of those enrolled, 536 were eligible for the study. Of the 536, researchers received contact information for 205. Primary reasons for not receiving information included mother declined to participate (47\%), the study was not yet introduced to the mother, but she did not have at least three visits (e.g. family was discharged) (31\%), and the study was not introduced to the mother during the first three visits (16\%). Of the 205 mothers who agreed to be contacted by the research team, 177 (86\%) consented and completed a baseline survey.

\footnotetext{
${ }^{1}$ For more information, see https://mchb.hrsa.gov/maternal-child -health-initiatives/home-visiting-overview.
}

$\overline{2}$ For HFA sites, the site also had to have completed the national model's site accreditation process. 


\section{Data Sources}

\section{Maternal and Visitor Surveys}

The baseline maternal surveys included questions about demographic characteristics, psychosocial well-being (e.g. depression and relationship security), and maternal and family functioning. They completed follow-up surveys 6 months later or, if pregnant at baseline, when the child was 6 months. The follow-up surveys included questions from baseline, but also included measures of child development, parent-child interaction, and ratings of home visiting.

Visitors completed web-based surveys in early 2012 . The survey captured demographic information, ratings of workplace culture, training, supervision, and psychosocial aspects of work (e.g. emotional exhaustion and morale).

\section{Program Management Information Systems (MIS)}

NJ HFA and PAT sites use a web-based, MIS developed by the State University of New York and NJ NFP sites use ETO provided by the NFP National Service Office. These systems enable sites to document service delivery.

\section{Measurement}

\section{Maternal Baseline Measures}

Emotional Availability Emotional availability includes depressive symptoms and relationship security as research has confirmed a link between them (Roberts et al. 1996; Strodl and Noller 2003). Each dimension of attachment has characteristics that can make one vulnerable to developing depression (Mikulincer and Shaver 2007). To assess depressive symptoms, we used the 12-item, Center for Epidemiologic Studies Depression Scale-Short Form (Ross et al. 1983). A total score was derived by summing items and scores $\geq 10$ indicated moderate to severe symptoms. Relationship security was measured using the 29-item, Attachment Style Questionnaire-Short Form (Karantzas et al. 2010). An exploratory factor analysis identified items loading onto anxiety and avoidance factors. The relationship anxiety subscale included 12 items $(\alpha=0.85)$ and the relationship avoidance subscale included eight items $(\alpha=0.76)$. Items were summed to create relationship anxiety and avoidance scores and then dichotomized such that scores above the theoretical median were considered 'high.' Mothers were considered low on emotional availability if they scored 'high' on relationship avoidance and scored positive for depressive symptoms or high on relationship anxiety.

Reasons for Enrolling in Home Visiting Mothers were given a list of 27 reasons for enrolling (e.g. "Want help finish- ing education") and were asked whether each was applicable. These reasons were grouped into 10 broad domains. Mothers were counted as enrolling for each domain if they endorsed any of the items within it.

\section{Maternal Follow-Up Measures}

Rating of the Visitor on Goal Alignment The 4-item, goals subscale from the Working Alliance Inventory-Home Visiting Short Form (Boller et al. 2014; Horvath and Greenberg 1994) was used to assess the mother's rating of her visitor regarding goals for home visiting (e.g. "My visitor and I are working toward mutually agreed upon goals"). Items were summed to yield overall scores ranging from 4 to 28 with high scores indicating greater alignment.

Rating of Satisfaction with the Program's Efforts to Address Reasons for Enrolling For each endorsed reason, mothers were asked how satisfied they were with the program's efforts to meet each need. A continuous score (range from 0 to 100) was created that represented the proportion of the reasons where the mother indicated being completely or very satisfied.

\section{Visitor Measures}

Perceptions of Organizational Climate Three first-order climate subscales of the Organization Social Context Measurement System (OSC; Glisson et al. 2008) were used to measure individual-level perceptions of emotional exhaustion, personalization, and personal accomplishment. Raw scores were converted to standardized T-scores with a mean of 50 and standard deviation of 10 . High scores on personalization and personal accomplishment are desirable and low scores are desirable for emotional exhaustion.

Morale The OSC also includes an individual-level measure of morale. Raw scores were converted to standardized T-scores with a mean of 50 and standard deviation of 10 . High scores are desirable.

\section{Program Engagement}

Engagement was defined as the total number of days from program enrollment to last completed home visit. For families still active, total number of days was calculated to the last home visit as of March 31, 2017.

\section{Analytic Plan}

Of the 177 mothers completing a baseline survey, 148 completed the follow-up (76 HFA, 70 NFP, and 2 PAT). When possible, analyses included all 148 mothers to maximize 
Table 1 Baseline maternal characteristics $(n=148)$

\begin{tabular}{ll}
\hline Maternal age in years (mean (SD)) & 22.7 (5.9) \\
Teen mother (<19 years old) & $36 \%$ \\
Enrolled prenatally & $71 \%$ \\
Race/ethnicity & \\
Hispanic/Latina & $24 \%$ \\
Black/African American & $39 \%$ \\
White, Non-Hispanic & $30 \%$ \\
Other & $7 \%$ \\
Married/living with partner & $28 \%$ \\
Highest grade completed & \\
$<$ HS & $28 \%$ \\
HS/GED & $32 \%$ \\
> HS, no degree & $27 \%$ \\
Degree past HS & $12 \%$ \\
Currently working & $20 \%$ \\
Receiving TANF/welfare & $19 \%$ \\
Low emotional availability & $32 \%$ \\
\hline
\end{tabular}

study power to detect meaningful differences. Analyses including visitor characteristics were limited to the 100 mothers whose visitor had completed a survey. These 100 mothers were served by 54 unique home visitors $(31 \mathrm{HF}$, 21 NFP, and 2 PAT). Mothers with a follow-up survey and mothers with visitor surveys did not differ from those without on baseline characteristics.

Simple linear regression was used for bivariate analyses. Path analysis was used to simultaneously test the direct effects of maternal and visitor characteristics on engagement and the mediating effects of ratings of the visitor and program satisfaction. Variables were considered for inclusion in the model if they were significant at the bivariate level $(\mathrm{p}<.10)$. To account for clustering of families within visitor, we used a full information maximum likelihood estimator with standard errors, parameter estimates, and a Chi square test statistic robust to nonnormality of the outcome variable and non-independence of observations (Graham 2009; Muthen and Muthen 1998-2017). Several measures were used to evaluate model fit, including Chi square, RMSEA, SRMR, CFI, and TLI. The path analysis was performed using Mplus v7.4.

\section{Results}

Mothers were young and most enrolled prenatally (Table 1). They were diverse in terms of race. About a third had education beyond high school and $20 \%$ were working. A third of mothers had low emotional availability. Half of visitors had a bachelor's degree or higher (Table 2). They had been in
Table 2 Visitor characteristics $(\mathrm{n}=54)$

\begin{tabular}{ll}
\hline Age & \\
\hline$<30$ & $21 \%$ \\
$30-39$ & $23 \%$ \\
$40-49$ & $33 \%$ \\
$50+$ & $23 \%$ \\
Race & \\
Hispanic/Latina & $33 \%$ \\
Black/African American & $28 \%$ \\
White, Non-Hispanic & $35 \%$ \\
Other & $4 \%$ \\
Highest level completed in school & \\
HS/GED & $14 \%$ \\
Some college, no degree & $24 \%$ \\
Associate's/vocational & $12 \%$ \\
Bachelor's or higher & $51 \%$ \\
Years in position (mean (SD)) & $4.7(3.9)$ \\
Organizational climate ${ }^{\mathrm{a}}$ (mean (SD)) & \\
Emotional exhaustion & $50.7(8.1)$ \\
Personalization & $49.4(8.7)$ \\
Personal accomplishment & $57.8(7.1)$ \\
Morale (mean (SD)) & $60.2(7.6)$ \\
\hline
\end{tabular}

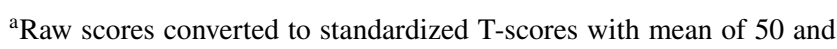
SD of 10

their positions an average of 4.7 years. Visitors reported high levels of morale, with the average score $>60$.

\section{Reasons for Enrolling and Satisfaction with the Program's Efforts}

Most mothers enrolled for many reasons; $82 \%$ endorsed reasons in four or more of the domains. Nearly all enrolled for child development and parenting and healthy pregnancy and child health (Table 3). Only a sixth enrolled for mental health. Reasons for enrolling varied by select characteristics, such as pre- or postnatal enrollment, ethnicity, and emotional availability. For example, compared to other mothers, mothers with low emotional availability enrolled for more reasons (6.6 vs. 5.7, p=.01) and were more likely to enroll for reasons related to education and employment (77 vs. $53 \%$, $\mathrm{p}=.01$ ) and other economic needs (58 vs. $40 \%, \mathrm{p}=.04)$.

Overall, mothers rated their visitors favorably on goal alignment (Table 3). Scores ranged from 9 to 28, with an average of $23.3(\mathrm{SD}=4.1)$. Most mothers reported being very or completely satisfied with the program's efforts around child development and parenting (79\%). They were least satisfied with efforts related to education and employment. On average, mothers were satisfied with program efforts on $71 \%$ of their reasons for enrolling. 
Table 3 Mothers' reasons for enrolling in home visiting and satisfaction with program efforts $(\mathrm{n}=148)$

\begin{tabular}{|c|c|c|}
\hline & $\begin{array}{l}\% \text { Mothers enrolling for } \\
\text { this reason }\end{array}$ & $\begin{array}{l}\% \text { Satisfied with } \\
\text { program efforts }^{\mathrm{a}}\end{array}$ \\
\hline Child development and parenting & 96 & 79 \\
\hline Healthy pregnancy and child health & 94 & 63 \\
\hline Social support & 77 & 57 \\
\hline Education and employment & 61 & 30 \\
\hline Income and benefits & 56 & 50 \\
\hline Primary care and insurance & 56 & 47 \\
\hline Family planning & 55 & 73 \\
\hline Other economic needs ${ }^{\mathrm{b}}$ & 46 & 31 \\
\hline Other maternal health and wellbeing ${ }^{\mathrm{c}}$ & 38 & 70 \\
\hline Mental health & 16 & 56 \\
\hline \multicolumn{3}{|c|}{ Mothers' ratings of the visitor and program (mean (SD)) } \\
\hline Maternal rating of visitor on goal alignment ${ }^{\mathrm{d}}$ & & $23.3(4.1)$ \\
\hline Overall satisfaction with program efforts ${ }^{\mathrm{e}}$ & & $71.3(26.8)$ \\
\hline \multicolumn{3}{|c|}{${ }^{a}$ Completely or very satisfied with program efforts for each reason noted within the domain } \\
\hline \multicolumn{3}{|c|}{${ }^{\mathrm{c}}$ Includes healthy adult relationships, help with smoking, and help with alcohol } \\
\hline \multicolumn{3}{|l|}{${ }^{\mathrm{d}}$ Possible range $4-28$} \\
\hline \multicolumn{3}{|l|}{${ }^{\mathrm{e}}$ Possible range $0-100$} \\
\hline
\end{tabular}

Table 4 Bivariate associations of maternal and visitor characteristics with mothers' ratings of the visitor and satisfaction with program efforts

\begin{tabular}{lrrrrr}
\hline & \multicolumn{2}{l}{$\begin{array}{l}\text { Rating of visitor } \\
\text { on goal alignment }\end{array}$} & \multicolumn{2}{l}{$\begin{array}{l}\text { Overall satis- } \\
\text { faction with } \\
\text { program efforts }\end{array}$} \\
\cline { 2 - 3 } Maternal characteristics & $\mathrm{B}$ & $\mathrm{p}$ & & $\mathrm{B}$ \\
Age & 0.12 & .04 & -0.12 & .74 \\
Hispanic & -0.12 & .87 & -1.92 & .71 \\
Enrolled prenatally & 0.15 & .84 & 13.44 & $<.01$ \\
Low emotional availability & -1.97 & $<.01$ & -7.74 & .10 \\
Visitor characteristics & & & & & \\
Organizational climate & & & & \\
$\quad$ Emotional exhaustion & -0.09 & .08 & 0.04 & .92 \\
$\quad$ Personalization & 0.03 & .50 & -0.21 & .53 \\
$\quad$ Personal accomplishment & 0.07 & .30 & -0.36 & .38 \\
Morale & 0.12 & $<.01$ & -0.11 & .83 \\
\hline
\end{tabular}

${ }^{\text {a }}$ Limited to mothers with a visitor who completed the web-based staff survey $(n=100)$. Models are clustered on visitor

\section{Bivariate Associations of Maternal and Visitor Characteristics with Ratings of the Visitor and Satisfaction with Program Efforts}

Maternal age and visitor morale were positively associated with ratings of the visitor on goal alignment (Table 4). In
Table 5 Factors for program engagement, bivariate associations

\begin{tabular}{lll}
\hline Bivariate associations & \multicolumn{2}{l}{$\begin{array}{l}\text { Total days } \\
\text { enrolled in home } \\
\text { visiting program }\end{array}$} \\
\cline { 2 - 3 } & $\mathrm{B}$ & $\mathrm{p}$ \\
\hline Maternal characteristics & & \\
Age & 10.5 & .07 \\
Hispanic & 133.0 & .10 \\
Enrolled prenatally & 67.6 & .37 \\
Low emotional availability & -174.2 & .02 \\
Visitor characteristics & & \\
Organizational climate & & \\
Emotional exhaustion & -13.4 & .01 \\
Personalization & 4.6 & .33 \\
Personal accomplishment & -0.9 & .89 \\
Morale & 10.1 & .09 \\
Maternal ratings of the visitor and program & & \\
Maternal rating of visitor on goal alignment & 24.1 & $<.01$ \\
Overall satisfaction with program efforts & 3.4 & .01 \\
\hline
\end{tabular}

${ }^{\mathrm{a}}$ Limited to mothers with a visitor who completed the web-based staff survey $(n=100)$. Models are clustered on visitor

contrast, low emotional availability and visitor emotional exhaustion were negatively associated with these ratings.

Prenatally enrolled mothers were more likely to report satisfaction with program efforts to address their reasons for enrolling; mothers with low emotional availability had lower satisfaction scores. 
Fig. 1 Direct effects of mother and visitor characteristics on days enrolled in the program. Red, solid arrows represent statistically significant direct effects at $\mathrm{p}<.05$. Green, dashed arrows represent direct effects significant at $\mathrm{p} \leq .10$, and black, dotted arrows represent non-significant direct effects $(\mathrm{p}>$.10). Curved arrows between maternal characteristics represent controlling for confounding effects of ethnicity and age in the model. Significance levels are not represented in curved arrows. Fit statistics: $\chi 2$ (9): 9.232, RMSEA $=0.016$, $\mathrm{SRMR}=0.054, \mathrm{CFI}=0.995$, $\mathrm{TLI}=0.991$. (Color figure online)

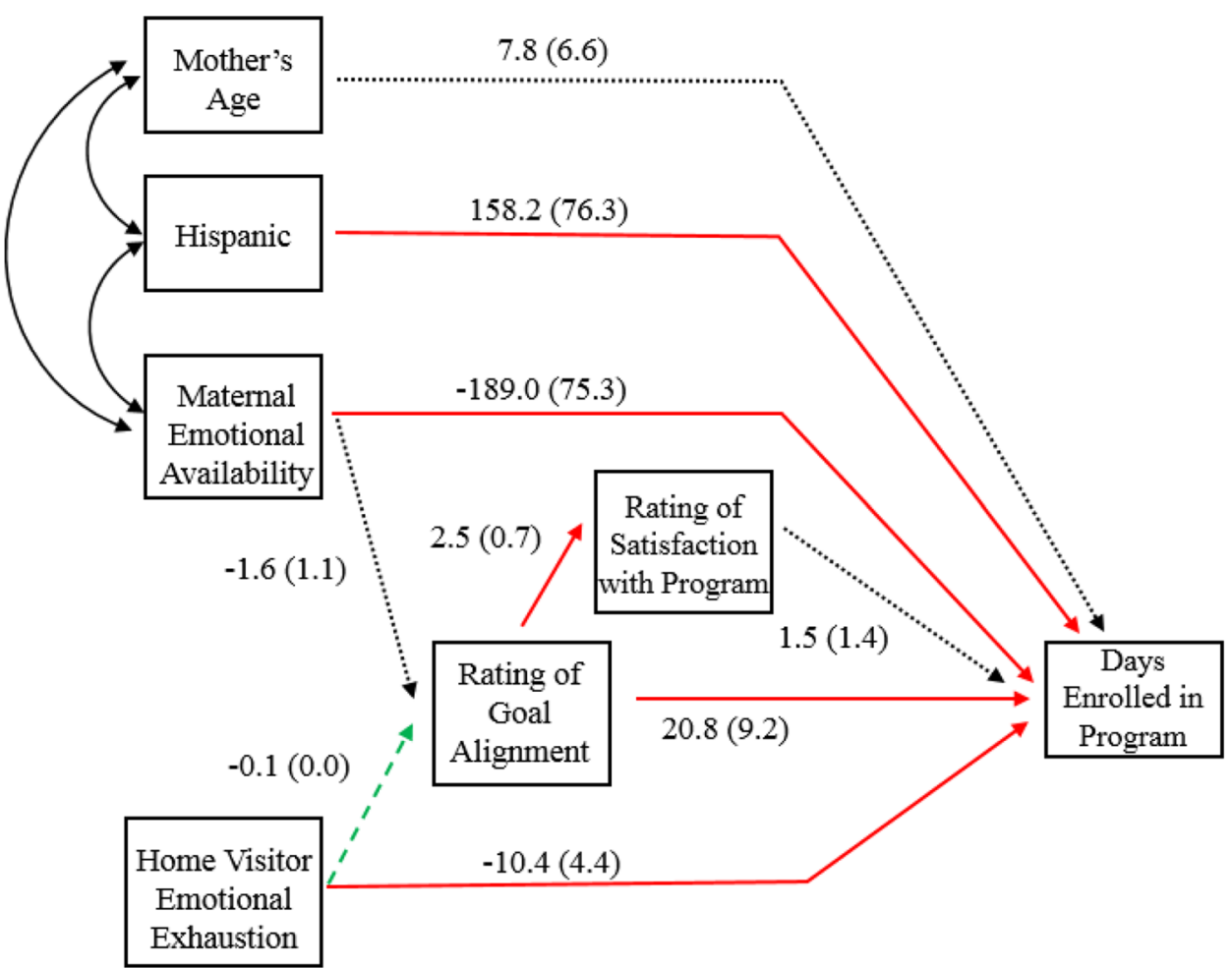

\section{Factors for Program Engagement-Bivariate Associations}

On average, mothers were enrolled for 616 days. Days enrolled increased as maternal age increased, Hispanic mothers were enrolled longer than non-Hispanic mothers and mothers with low emotional availability were enrolled fewer days than other mothers (Table 5). Visitor emotional exhaustion and morale were significantly related to engagement.

Mothers' ratings of the visitor on goal alignment and their satisfaction with the program's effort to address reasons for enrolling were positively associated with engagement.

\section{Factors for Program Engagement-Mediational Path Model}

In the path model, low maternal emotional availability and higher visitor emotional exhaustion were significantly associated with fewer days enrolled after controlling for age and ethnicity (Fig. 1). Ratings of the visitor on goal alignment were positively associated with number of days enrolled.

In this model, the total mediational effect of ratings of the visitor on goal alignment and program satisfaction on the relationship between emotional availability and length of enrollment were not statistically significant $(B=-40.03$, $\mathrm{p}=.15$ ). Likewise, ratings of the visitor and program did not significantly mediate the relationship between visitor emotional exhaustion and length of enrollment $(B=-2.08$, $\mathrm{p}=.14)$. Fit statistics for this model all fell within the good to very good range.

To further explore these pathways, we repeated these analyses separately for mothers with low and adequate emotional availability. Visitor emotional exhaustion was significantly associated with fewer days enrolled, but only for mothers with adequate emotional availability (not shown; $B=-13.89, \mathrm{p}=.01$ ). Additionally, ratings of goal alignment were significantly associated with longer enrollment, but only for mothers with low emotional availability (not shown in figure; $B=32.83, \mathrm{p}=.01$ ).

\section{Discussion}

This study investigated the associations among mother and visitor psychosocial characteristics, mothers' ratings of the visitor on goal alignment, and satisfaction with program efforts to address their needs with length of enrollment. Mothers enrolled in home visiting for many reasons, were most satisfied with program efforts to address reasons related to parenting and child development and generally rated their visitors highly on goal alignment. Mothers who rated their visitor highly on goal alignment stayed in the program longer. Additionally, low emotional availability and visitor emotional exhaustion were both negatively associated with a family's length of enrollment. Mothers with low 
emotional availability left home visiting about 6 months earlier than other mothers. Ratings of the visitor and program did not mediate the association of maternal and visitor characteristics on program engagement. Exploratory analyses suggested that ratings of the visitor on goal alignment were a stronger predictor of engagement for mothers with low emotional availability compared to mothers with adequate emotional availability.

These findings are consistent with other work, particularly Korfmacher et al. (2007), who found that maternal ratings of the relationship with her visitor predicted the amount of time spent in the program. The current study extends previous research by incorporating maternal and visitor characteristics and ratings of their relationship to help explain the effect on engagement.

Addressing maternal psychosocial risks is a challenge; studies have cited mental health concerns as one of the most common challenging situations facing visitors (Harden et al. 2010; Tandon et al. 2008). Although only $16 \%$ of mothers in this study enrolled for mental health reasons, one-third of mothers experienced low emotional availability, defined here as high levels of relationship avoidance combined with depressive symptoms and/or high levels of relationship anxiety. This is similar to rates found in other studies (CluxtonKeller et al. 2014; McFarlane et al. 2013). These mothers were at a substantial risk of leaving the program prematurely and these findings suggest that this risk may be decreased when mothers and visitors are aligned on goals.

Visitor emotional exhaustion was also negatively associated with engagement. In the path model, emotional exhaustion was associated with a decrease in goal ratings. It is possible that visitors who are more emotionally exhausted are less responsive to addressing goals of mothers. And in fact, the exploratory results suggest that this is of particular concern when serving mothers with adequate emotional availability; when visitors are more exhausted, these mothers leave the program sooner. This would indicate that the workrelated characteristics of visitors are important, particularly when serving mothers with adequate emotional availability.

We did not find that satisfaction with program efforts was a predictor of days enrolled in the path model. This is consistent with Korfmacher et al.'s (2007) finding that when both ratings of the helping relationship and satisfaction with the program were included in models together, ratings of the program were not as strong of a predictor of engagement as direct ratings of the visitor.

In this study, Hispanic mothers endorsed more reasons for enrolling, were more likely to enroll for reasons related to primary care, mental health, and maternal health and wellbeing, and stayed enrolled in the program longer than nonHispanic mothers, which is consistent with other research (McGuigan et al. 2003; O'Brien et al. 2012). Given the transition to precision home visiting, the differentiation of what works, for whom, in what contexts to achieve specific outcomes, being led by HRSA, future work should examine how these pathways vary across race and ethnic groups. ${ }^{3}$

\section{Methodological Considerations}

Study findings should be interpreted in light of methodological strengths and limitations. One strength is that the sample was drawn from a large number of local programs using three home visiting models. While the models vary slightly in who they target for services, all three models are similar in the intended length and intensity of services and in their primary outcomes for families (Michalopoulos et al. 2015). While the current study was not designed with the intention to test for differences across models, future work might consider whether models differ in how visitors work with families to set goals which align with their reasons for enrolling. Another strength is the use of path analysis. Since variables can be both independent and dependent, path analysis allows for the simultaneous estimation of all direct and mediating effects.

On the other hand, visitors played a role in recruiting the sample. This might have introduced bias. Also, sample size was small, particularly in analyses including visitor data, limiting power to detect meaningful associations. A post-hoc power analysis using a Monte Carlo simulation was carried out on the mediational path model and results indicated a lack of statistical power which could explain the non-significant, mediational effects.

A final limitation relates to measurement of family engagement. Duration of enrollment is easily measured, but is a simplistic indicator of true engagement. Future research should extend its focus to include measures of parents' actual participation in visits as indicated by shared decisionmaking, observational measures of how well the visitor communicates with mothers to build partnership toward reaching goals, and how visitors tailor the content of visits to align with mothers' goals.

\section{Implications}

Family engagement in home visiting is a critical issue for the field. Visitor alignment with mothers on goals and responsiveness to reasons for enrolling appear to be effective in promoting engagement, especially for some mothers. Programs should formally identify mothers' reasons for enrolling early on so that family goal plans, a strategy to build a strong working alliance, reflect the goals that are important to the family from the start. Implementation systems should be strengthened to support visitors in developing and using

\footnotetext{
${ }_{3}$ For more information, see http://www.hvresearch.org.
} 
goal plans and with funding through a HRSA Innovation Award, New Jersey and Maryland are partnering to design and test elements of a goal plan strategy (GPS) implementation system. ${ }^{4}$ The purpose is to promote engagement by improving visitors' competence to respond to a family's reasons for enrolling, by making it easier for visitors to do this, and by reinforcing them in doing so.

Services should be individualized not only to a mother's reasons for enrolling but also to her emotional availability. Most programs already screen for depression at enrollment or at a time relative to the child's birth (Michalopoulos et al. 2015). Based on the current study, as well as our broader research, we feel it is important that programs consider relationship security in tailoring services. Work is needed to design and test strategies for this. Visitors are in a unique position not only to use formal screening tools but also to recognize and respond to mothers' cues regarding their emotional well-being - both depressive symptoms and relationship security. If home visiting enrolls mothers with low emotional availability, we need to adjust our expectations of their engagement, our visitors' strategies to personalize communication strategies to promote their engagement, or both. The high prevalence of low emotional availability underscores the importance of precision home visiting to improve on our current service models.

Acknowledgements The authors thank the NJ Department of Health and the NJ Department of Children and Families, the NJ Home Visiting Initiative partners, and local program leadership and staff for their ongoing support of evaluation and research and commitment to improving services for families in $\mathrm{NJ}$ while advancing the field nationally. We would like to acknowledge support for the statistical analysis from the National Center for Research Resources and the National Center for Advancing Translational Sciences (NCATS) of the National Institutes of Health through Grant Number 1UL1TR001079. Research activities were funded under the following federal support: The US Department of Health and Human Services (HHS), Administration for Children and Families, Children's Bureau, Office of Child Abuse and Neglect, Supporting Evidence-Based Home Visiting to Prevent Child Maltreatment (EBHV) (2008-2011: Contract No. HHS-2008-ACF-ACYF-CA-0130), HHS, Health Resources and Services Administration (HRSA), Maternal, Infant, Early Childhood Home Visiting Program (MIECHV) (NJ 2015 Formula Grant Award X02MC28235; NJ 2015 Competitive Grant Award D89MC28268).

Open Access This article is distributed under the terms of the Creative Commons Attribution 4.0 International License (http://creativeco mmons.org/licenses/by/4.0/), which permits unrestricted use, distribution, and reproduction in any medium, provided you give appropriate credit to the original author(s) and the source, provide a link to the Creative Commons license, and indicate if changes were made.

\section{References}

Boller, K., Daro, D., Del Grosso, P., Cole, R., Paulsell, D., Hart, B., ... Hargreaves, M. (2014). Making replication work: Building infrastructure to implement, scale-up, and sustain evidence-based early childhood home visiting programs with fidelity. Princeton, NJ: Mathematica Policy Research.

Cho, J., Terris, D. D., Glisson, R. E., Bae, D., \& Brown, A. (2017). Studies beyond family demographics, community risk influences maternal engagement in home visiting. Journal of Child and Family. https://doi.org/10.1007/s10826-017-0803-8.

Cluxton-Keller, F., Burrell, L., Crowne, S., McFarlane, E., Tandon, S. D., Leaf, P. J., \& Duggan, A. (2014). Maternal relationship insecurity and depressive symptoms as moderators of home visiting impacts on child outcomes. Journal of Child and Family Studies, 23(8), 1430-1443.

Daro, D., McCurdy, K., Falconnier, L., \& Stojanovic, D. (2003). Sustaining new parents in home visitation services: Key participant and program factors. Child Abuse \& Neglect, 27(10), 1101-1125.

Duggan, A., Caldera, D., Rodriguez, K., Burrell, L., Rohde, C., \& Crowne, S. S. (2007). Impact of a statewide home visiting program to prevent child abuse. Child Abuse \& Neglect, 31(8), 801-827.

Duggan, A., Minkovitz, C. S., Chaffin, M., Korfmacher, J., BrooksGunn, J., Crowne, S., ... Harwood, R. (2013). Creating a national home visiting research network. Pediatrics, 132(Supplement 2), S82-S89.

Girvin, H., DePanfilis, D., \& Daining, C. (2007). Predicting program completion among families enrolled in a child neglect preventive intervention. Research on Social Work Practice, 17, 674-685.

Glisson, C., Landsverk, J., Schoenwald, S., Kelleher, K., Hoagwood, K. E., Mayberg, S., \& Green, P. (2008). Assessing the organizational social context (OSC) of mental health services: Implications for research and practice. Administration and Policy in Mental Health and Mental Health Services Research, 35(1-2), 98-113.

Graham, J. W. (2009). Missing data analysis: Making it work in the real world. Annual Review of Psychology, 60, 549-576.

Harden, B., Denmark, N., \& Saul, D. (2010). Understanding the needs of staff in Head Start programs: The characteristics, perceptions, and experiences of visitors. Children and Youth Services Review, 3, 371-379.

Horvath, A. O., \& Greenberg, L. S. (Eds.). (1994). The working alliance: Theory research and practice. New York: Wiley.

Karantzas, G. C., Feeney, J. A., \& Wilkinson, R. (2010). Is less more? Confirmatory factor analysis of the attachment style questionnaires. Thousand Oaks: Sage. https://doi.org/10.1177/02654 07510373756.

Korfmacher, J., Green, B., Spellmann, M., \& Thornburg, K. R. (2007). The helping relationship and program participation in early childhood home visiting. Infant Mental Health Journal, 28(5), 459-480.

Latimore, A. D., Burrell, L., Crowne, S., Ojo, K., Cluxton-Keller, F., Gustin, S., ... Duggan, A. (2017). Exploring multilevel factors for family engagement in home visiting across two national models. Prevention Science. https://doi.org/10.1007/s11121-017-0767-3.

McFarlane, E., Burrell, L., Crowne, S., Cluxton-Keller, F., Fuddy, L., Leaf, P. J., \& Duggan, A. (2013). Maternal relationship security as a moderator of home visiting impacts on maternal psychosocial functioning. Prevention Science, 14(1), 25-39.

McFarlane, E., Burrell, L., Fuddy, L., Tandon, S. D., Derauf, C., Leaf, P., \& Duggan, A. (2010). Association of visitors' and mothers' attachment style with family engagement. Journal of Community Psychology, 38, 541-556.

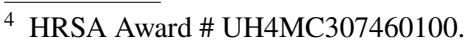


McGuigan, W. M., Katzev, A. R., \& Pratt, C. C. (2003). Multi-level determinants of retention in a home-visiting child abuse prevention program. Child Abuse \& Neglect, 27(4), 363-380.

Michalopoulos, C., Lee, H., Duggan, A., Lundquist, E., Tso, A., Crowne, S., ... Knox, V. (2015). The mother and infant home visiting program evaluation: Early findings on the maternal, infant, and early childhood home visiting program. OPRE Report $2015-$ 11. Washington, DC: Office of Planning, Research and Evaluation, Administration for Children and Families, U.S. Department of Health and Human Services.

MIECHV Technical Assistance Coordinating Center. (2015). MIECHV Issue Brief on Family Enrollment and Engagement. Retrieved from https://mchb.hrsa.gov/sites/default/files/mchb/MaternalCh ildHealthInitiatives/HomeVisiting/tafiles/enrollmentandengagem ent.pdf.

Mikulincer, M., \& Nachshon, O. (1991). Attachment styles and patterns of self-disclosure. Journal of Personality and Social Psychology, 61(2), 321-331.

Mikulincer, M., \& Shaver, P. R. (2007). Attachment in adulthood: Structure, dynamics, and change. New York: Guilford.

Muthén, L. K., \& Muthén, B. O. (1998-2017). Mplus user's guide. Eighth Edition. Los Angeles, CA: Muthén \& Muthén.

O’Brien, R. A., Moritz, P., Luckey, D. W., McClatchey, M. W., Ingoldsby, E. M., \& Olds, D. L. (2012). Mixed methods analysis of participant attrition in the nurse-family partnership. Prevention Science, 13(3), 219-228.

Roberts, J. E., Gotlib, I. H., \& Kassel, J. D. (1996). Adult attachment styles and symptoms of depression: The mediating role of dysfunctional attitudes and low self-esteem. Journal of Personality and Social Psychology, 70, 310-320.

Ross, C. E., Mirowsky, J., \& Huber, J. (1983). Dividing work, sharing work, and in-between: Marriage patterns and depression. American Sociological Review, 48, 809-823.

Sharp, E. A., Ispa, J. M., Thornburg, K. R., \& Lane, V. (2003). Relations among mother and visitor personality, relationship quality, and amount of time spent in home visits. Journal of Community Psychology, 31(6), 591-606.

Stevens, J., Ammerman, R. T., Putnam, F. W., Gannon, T., \& Van Ginkel, J. B. (2005). Facilitators and barriers to engagement in home visitation: A qualitative analysis of maternal, provider, and supervisor data. Journal of Aggression, Maltreatment \& Trauma, 11(4), 75-93.

Strodl, E., \& Noller, P. (2003). The relationship of adult attachment dimensions to depression and agoraphobia. Personal Relationships, 10, 171-185.

Tandon, S. D., Mercer, C. D., Saylor, E. L., \& Duggan, A. K. (2008). Paraprofessional visitors' perspectives on addressing poor mental health, substance abuse, and domestic violence: A qualitative study. Early Childhood Research Quarterly, 23(3), 419-428.

Tandon, S. D., Parillo, K., Mercer, C., Keefer, M., \& Duggan, A. K. (2008). Engagement in paraprofessional home visitation: Families' reasons for enrollment and program response to identified reasons. Women's Health Issues, 18(2), 118-129. 